\title{
Association between Overweight, Health Behaviors, and Insulin Resistance in School Children
}

\author{
V. Hirschler, ${ }^{1}$ C. G. Molinari, ${ }^{2}$ and C. Gonzalez ${ }^{3}$ \\ ${ }^{1}$ Department of Nutrition, Hospital Durand Buenos Aires, 1006 Capital Federal, Argentina \\ ${ }^{2}$ School of Pharmacy and Biochemistry, University of Buenos Aires, 1121 Buenos Aires, Argentina \\ ${ }^{3}$ School of Medicine, University of Buenos Aires, 1121 Buenos Aires, Argentina \\ Correspondence should be addressed to V. Hirschler, vhirschler@intramed.net
}

Received 4 November 2011; Accepted 7 December 2011

Academic Editors: D. M. Ivanovic, J. Vignerova, and A. Zaborskis

Copyright (๑) 2012 V. Hirschler et al. This is an open access article distributed under the Creative Commons Attribution License, which permits unrestricted use, distribution, and reproduction in any medium, provided the original work is properly cited.

The aim of the paper was to determine the association between children's BMI, health behaviors, and HOMA-IR. 1065 students $(535 \mathrm{M})$ aged $9.5 \pm 2.1 \mathrm{y}$ from 6 schools were examined. Questionnaires for healthy habits were completed. As all components could not contribute equally to overweight/obesity (OW/OB), a multiple regression analysis was done with BMI as the dependent variable. Those components which were associated with BMI were totaled to establish the score. Data also included Tanner, lipids, insulin, and glucose. 165 (15.5\%) of the children were OB (BMI > 95\%ile per CDC norms), and $152(14.3 \%)$, OW (85 $\leq$ BMI < 95\%ile). Multiple logistic regression analysis showed a positive association between children's OW/OB and HOMA-IR (OR, 2.42 (95\% CI 1.97-2.98)), and an inverse association with healthy score (OR, 0.66 (95\% CI 0.52-0.85)) adjusted for Tanner and gender. Our results suggest that this is an easy score that could be used to predict children's OW/OB; however additional longitudinal studies should be done to confirm these findings.

\section{Background}

The worldwide epidemic of obesity $(\mathrm{OB})$, resulting from changes in lifestyle characterized by the lack of physical activity and an energy-dense diet, has contributed to the creation of a new situation in which it is estimated that complications of overweight (OW) will soon surpass undernutrition as the leading causes of death in low-income communities [1]. Although the causes of $\mathrm{OB}$ in children are multifaceted, the recent upsurge in pediatric $\mathrm{OB}$ could be explained by changes in the availability of high caloric "fast" food, and soft drinks, an increase in time spent watching television, and a decrease in the opportunities for physical activity in schools and communities [2]. Many studies showed that high levels of body mass index (BMI, $\mathrm{kg} / \mathrm{m}^{2}$ ) among children and adolescents were associated with adverse levels of lipids, insulin, and blood pressure, all components of the metabolic syndrome [3-5]. Different reports $[6,7]$ show that exposure to $\mathrm{OB}$ in early life significantly contributed to the development of atherosclerosis and cardiovascular disease later in life.
The objective of this study was to determine the association between children's OW/OB and lifestyle behaviors and insulin resistance in elementary school children.

\section{Methods}

Subjects were 1065 children (525 males) aged $9.54 \pm 2.08$ years, age range 5.5-14.9 years, in 6 randomly selected elementary schools from the low-income suburbs of western Buenos Aires. Children were studied between April 2007 and March 2008. We calculated the sample size based on the prevalence of OW/OB in children reported in other elementary school studies in Buenos Aires [8]. Because the prevalence of OW/OB was approximately $33 \%$ among children in a similar population [8], the sample size was estimated to achieve that percentage with an error lower than 0.03 . The sample size consistent with this error was 1000 children.

Exclusion criteria included the following: missing BMI information, not being in the fasting state for at least 10 
hours, known diabetes or other chronic disease, the use of medication that would affect blood pressure or glucose or lipid metabolism, the informed consent not being signed, and self-reported pregnancy at the time of the examination. Of the 1137 children recruited from six schools, one was taking a thyroid medication, 31 were not in the fasting state, 12 were missing the BMI information, and 28 declined to participate. All subjects were examined by the same physician. The study was approved by the Human Rights Committee of Durand Hospital in Buenos Aires. Each subject and parent gave written informed consent after an explanation of the studyand before its initiation.

Socioeconomic characteristics included age, parental level of education, and the presence or absence of a refrigerator and/or a dirt floor. Mothers were asked to define the number of years they attended elementary school, if they completed elementary school or high school, and whether or not they had a university degree.

Mothers were asked about their children's lifestyle behaviors. Questionnaires were completed by the same pediatrician $(\mathrm{VH})$ as mothers generally had a low education level and may not have fully understood the questions. The questionnaires were preexamined by a statistician and a psychologist and were validated by administering them twice in two weeks to a pilot group of 100 mothers. Food frequency questionnaires are an acceptable measure of patterns of intake [9]. Mothers recorded the participants' daily consumption of vegetables and/or fresh fruit, glasses of milk, and sweetened beverages, the number of meals consumed with the family, and hours of TV viewing, as $1,2,3,4$, or $\geq 5$ as well as the presence of a TV set in the children's bedrooms, and whether or not breakfast was typically consumed. Standard serving sizes and food models were provided as a reference for intake estimation. To assess physical activity, a four-level index that ranked participants according to the number of blocks walked daily was used $(<5$, $5-10,10-20, \geq 20$ blocks daily).

To maximize adjustment for lifestyle factors that may confound associations between lifestyle habits and OW/OB, we created a healthy propensity score based on the following lifestyle factors, coded as 0 for unhealthy, and 1 for healthy as recommended [10]. The daily lifestyle recommendations [10] were as follows: two cups of milk for children aged 4-8 years and three cups of milk for children aged 9-14 years, for fruit and vegetables 3 or more portions, for sweet beverages one or fewer servings, for TV viewing equal to or less than two hours, the absence of a TV set in the child's bedroom, and breakfast intake. As all component factors could not contribute equally to OW/OB, a multiple linear regression analysis was done with BMI percentile as the dependent variable and each component of the health score as independent variables. To determine the weight of each component in the score, those components which were significantly associated with BMI percentile were multiplied by the beta-standardized coefficient of the regression analysis. Therefore, each component of the score was represented by a number according to their weighted contribution to BMI percentile. Then, the numbers were totaled to establish the score. We also created four categories with three being the healthiest and zero being the least healthy.

The physical examination included determination of the stage of puberty according to the criteria of Tanner [11]. Tanner stage was performed in 1001 children because 64 children refused to be examined.

About $85 \%$ of the population of Argentina is of European descent (largely Spanish and Italian), with the remainder of mixed European and South American Indian (12\%) or mixed Indian (3\%) descent [12].

Height and weight were measured with subjects wearing light clothing and without shoes. Height was recorded to the nearest $0.1 \mathrm{~cm}$ with a wall-mounted stadiometer. Weight was measured to the nearest $0.1 \mathrm{~kg}$ on a medical balance scale. BMI was calculated as weight in kilograms divided by height in meters squared. Normal weight children were defined as having a BMI $<85$ th percentile. OW and $\mathrm{OB}$ were defined as a BMI 85th to 94th and $\geq 95$ th percentile, respectively, for age and sex per Centers for Disease Control standards for US children. BMI $z$-score (BMI- $z$ ) was also determined [13].

Waist circumference measurement was taken at the level of the umbilicus with the child in the standing position, without clothing covering the waist area, using a nonelastic flexible tape measure and recorded to $0.1 \mathrm{~cm}$. Central $\mathrm{OB}$ was defined for children as waist circumference $\geq 90$ th percentile, according to sex and age, based on approximately 3000 normal Argentinean children (unpublished data).

Three separate blood pressure measurements were recorded by a trained technician using a random-zero sphygmomanometer after the participant was seated at rest for 5 minutes. The averages of the least two measurements of systolic and diastolic blood pressures were used. Because normal pediatric blood pressure varies significantly, we used the National Heart, Lung and Blood Institute's recommended cut point for age, gender, and height [14].

Baseline blood samples were obtained from subjects after fasting for 10 hours, for measurement of levels of glucose, lipids, and insulin. Plasma glucose was obtained by the glucose oxidase technique, and serum lipids were measured with a Hitachi Modular P analyzer (Hitachi High Technologies Corp., Tokyo, Japan). Serum insulin levels were determined by radioimmunoassay(Diagnostic Products, Los Angeles, CA, USA) and did not cross-react with proinsulin or C-peptide (\%CV 5.2-6.8\%).

Metabolic syndrome is a constellation of metabolic abnormalities that predicts premature coronary artery disease. Criteria analogous to the National Cholesterol Education Program Adult Treatment Panel III definition were used for children [15]. Briefly, metabolic syndrome was defined as the presence of $\geq 3$ of the following 5 conditions: (1) central OB (waist circumference $>90$ th percentile), (2) fasting triglycerides $>110 \mathrm{mg} / \mathrm{dL}$, (3) HDL-C $<40 \mathrm{mg} / \mathrm{dL}$, (4) blood pressure $>90$ th percentile for age, gender, and height, (5) fasting glucose $>100 \mathrm{mg} / \mathrm{dL}$.

The degree of insulin resistance was determined with the use of a homeostatic model assessment (HOMA-IR) [16]. HOMA-IR has been validated in children and was strongly correlated with insulin resistance [17]. The following equation for HOMA-IR index was used: fasting insulin 
$(\mathrm{uU} / \mathrm{l}) \times$ fasting glucose $(\mathrm{mmoL} / \mathrm{l}) / 22.5)$ [18]. HOMA-IR was categorized in quartiles for analysis and HOMA-IR $\geq$ III quartile was considered insulin resistance.

\section{Data Analysis}

Chi-squared test was used to compare proportions. When more than $20 \%$ of the cells had expected frequencies less than 5, Fisher's exact test was used. The observed prevalence was presented in percentage and $95 \%$ confidence interval. The fit to normal distribution of continuous variables was assessed using the Shapiro-Wilks test. When comparing two groups with normally distributed data, a Students $t$-test was performed.

Multiple linear regression analysis was done to examine the relationship between BMI percentile as the dependent variable and lifestyle behaviors as the independent variables. The probability of being OW/OB in each HOMA-IR quartile adjusted for gender and Tanner stages was analyzed using logistic regression analysis. Multiple logistic regression analysis was also performed using $\mathrm{OW} / \mathrm{OB}$ as the dependent variable and HOMA-IR, healthy score, gender, and Tanner stages as the independent variables.

Observed associations were expressed as OR with 95\% confidence intervals.

$P$ values $<0.05$ were considered significant. Data were presented as mean \pm standard deviation (SD). Analyses were done using the SPSS (Chicago, IL) statistical software package SPSS version 17.0.

\section{Results}

All families were in the low socioeconomic class: $77.8 \%$ of parents had an elementary education or less, $7.8 \%$ of the families did not have a refrigerator, and $4.1 \%$ had a dirt floor. One hundred and sixty five (15.5\%) of the children were OB (BMI $\geq 95 \%$ ile per CDC norms), and 152 (14.3\%) were OW (BMI $\geq 85<95 \%$ ile). The prevalence of waist circumference $\geq 90$ th percentile was $262 / 1065$ (24.6\%). The social worker report showed that all of the children in these neighborhoods attended elementary school. Fifty eight \% (587/1001), 23.4\% (234/1001), $14.0 \%(140 / 1001), 3.9 \%(39 / 1001)$, and $0.1 \%$ (1/1001) were at Tanner stages 1, 2, 3, 4, and 5, respectively. As only 1 child was at Tanner stage 5, we merged it with Tanner stage 4 for the analysis.

4.1. Physical and Metabolic Characteristics. Mean levels of various characteristics in both sexes are presented in Table 1 . Girls were slightly older and had higher mean triglyceride levels, HOMA-IR, and insulin levels, and lower HDL-C and glucose levels. The prevalence of Tanner stage 1 (prepubertal) was significantly lower in girls (40.5\%) than in boys $(76.9 \%)$ $(P<0.001)$, as expected with earlier pubertal maturation in girls (Table 1). There was not a significant difference in BMI, $z$-BMI, waist circumference, systolic blood pressure, and in the prevalence of $\mathrm{OW}$ and $\mathrm{OB}$ between genders. However, there was a higher prevalence of central $\mathrm{OB}$ in girls than in boys.
4.2. $O W / O B$ and Components of Metabolic Syndrome. Within the sample, the risk factors of central obesity $24.60 \%$, (95\% CI 22.01-17.19\%) and low HDL-C $18.18 \%$ (95\% CI 15.46-20.91\%) were common, while high triglycerides $11.04 \%$, (95\% CI 8.83-13.25\%), hypertension 3.15\% (95\% CI $2.10-4.21 \%$ ), and impaired fasting glucose $0.78 \%$ (95\% CI $0.16-1.40 \%)$ were infrequent in the sample. None had diabetes. Approximately $40 \%$ of the children had at least one component of metabolic syndrome, and $15 \%$ of the children had two or more components for the metabolic syndrome. The prevalence of metabolic syndrome was $4.2 \%$ and there was not a significant difference between genders.

Mean levels of various characteristics according to $\mathrm{OW} / \mathrm{OB}$ are presented in Table 3 . There was a higher prevalence of central $\mathrm{OB}$, hypertension, low HDL-C, and hypertriglyceridemia among children with OW/OB (Table 2). Mean values of BMI, triglycerides, systolic blood pressure, diastolic blood pressure, glucose, insulin, and HOMA-IR were significantly higher while HDL-C was significantly lower in the group of children with OW/OB (Table 2).

4.3. Lifestyle Habits. Approximately $94 \%$ of the children drank one or more glasses of sweet beverages per day, only $24.3 \%$ drank more than two glasses of milk per day, $62.4 \%$ watched TV more than two hours per day, $42 \%$ had TV sets in their bedrooms, $0.7 \%$ did not have any family meals, $2 \%$ walked 20 or more blocks per day, $13.7 \%$ did not eat breakfast, and $26.7 \%$ ate three or more servings of fruits and vegetables per day. Ninety-one percent of the time, the sweet beverages consumed by children were juices made from concentrated powder diluted in water. Only $2.7 \%$ drank lowfat or skim milk, as recommended for children who are older than 2 years [10].

Each component of the score was weighted using a linear regression model and BMI percentile as the dependent variable (Table 3 ). Those components which were significantly associated in the regression analysis contributed equally to BMI percentile (Table 3 ) and those components which were not significantly associated in the regression analysis were excluded from the score. Therefore the health score included breakfast intake, glasses of milk intake, and TV viewing, whereas sweet beverages intake, blocks walked, family meals, and the presence of a TV set in their bedrooms were excluded (Table 3). Thus the health score had a range from 0 (least healthy) to 0.24 (most healthy). As the distance between each variable was equal, we created four categories with three being the healthiest and zero being the least healthy.

There was not a significant difference in the distribution of the health score categories between genders $(P=0.08)$, even though differences in some categories were suggested in Figure 1. There was a significant difference in the distribution of the health score categories between normal-weight and OW/OB children $(P<0.01)$ (Figure 2$)$. There was a higher proportion of children in the two lower health categories in OW/OB than in normal weight children (50\% versus $38.5 \%$; $P<0.01$ ). Furthermore, category one (less healthy) was the most frequent in OW/OB group whereas category two (healthier) was more frequent in normal weight children. 
TABLE 1: Clinical and metabolic characteristics according to sex.

\begin{tabular}{|c|c|c|}
\hline & Boys & Girls \\
\hline$N=1065$ & 525 & 540 \\
\hline$\%$ & $49.3 \%$ & $50.7 \%$ \\
\hline Age (years) & $9.42 \pm 2.00$ & $9.67 \pm 2.15^{*}$ \\
\hline waist circumference $(\mathrm{cm})$ & $63.89 \pm 10.10$ & $64.86 \pm 10.94$ \\
\hline $\operatorname{BMI}\left(\mathrm{kg} / \mathrm{m}^{2}\right)$ & $18.42 \pm 3.60$ & $18.81 \pm 3.95$ \\
\hline BMI $z$-score & $0.46 \pm 1.08$ & $0.43 \pm 1.08$ \\
\hline Systolic BP (mm Hg) & $92.52 \pm 12.64$ & $92.67 \pm 13.39$ \\
\hline Colesterol (mg/dL) & $152.67 \pm 26.46)$ & $154.40 \pm 27.74$ \\
\hline Triglyceride (mg/dL) & $69.72 \pm 31.82^{* *}$ & $80.51 \pm 37.96^{* *}$ \\
\hline HDL-C (mg/dL) & $52.37 \pm 11.85^{*}$ & $50.26 \pm 11.73^{*}$ \\
\hline Glucose (mg/dL) & $76.86 \pm 8.90^{*}$ & $75.57 \pm 8.14)^{*}$ \\
\hline Insulin (UI/mL) & $3.92 \pm 3.14^{* *}$ & $5.71 \pm 4.61^{* *}$ \\
\hline HOMA-IR & $0.76 \pm 0.64^{* *}$ & $1.07 \pm 0.88^{* *}$ \\
\hline Tanner $1(\% ; 95 \%$ CI $)$ & $77.03(73.32-80.75)^{* *}$ & $40.86(36.59-45.14)^{* *}$ \\
\hline OW (\%; 95\% CI) & $14.29(11.29-17.28)$ & $15.81(12.69-18.93)$ \\
\hline Obese $(\% ; 95 \%$ CI $)$ & $14.26(11.31-17.21)$ & $15.19(12.16-18.21)$ \\
\hline $\begin{array}{l}\mathrm{WC} \geq 90 \text { percentile }(\% ; 95 \% \\
\mathrm{CI})\end{array}$ & $16.95(13.74-20.16)^{* *}$ & $32.04(28.10-35.97)^{* *}$ \\
\hline
\end{tabular}

Data are in Mean \pm SD and observed prevalence is in percentage, (95\% confidence interval); ${ }^{* *} P<0.01 ;{ }^{*} P<0.05$.

TABle 2: Patient characteristics according to the presence of OW/OB.

\begin{tabular}{|c|c|c|c|}
\hline & $\begin{array}{l}\text { Normal weight } \\
\quad(n=749)\end{array}$ & $\begin{array}{l}\text { OW/OB } \\
(n=316)\end{array}$ & $\begin{array}{l}\text { Significance } \\
P<0.05\end{array}$ \\
\hline Age (years) & $9.51 \pm 2.11$ & $9.61 \pm 2.00$ & 0.46 \\
\hline Waist circumference $(\mathrm{cm})$ & $60.04 \pm 6.78$ & $74.67 \pm 10.72$ & $<0.01$ \\
\hline $\operatorname{BMI}\left(\mathrm{kg} / \mathrm{m}^{2}\right)$ & $16.75 \pm 1.80$ & $23.04 \pm 3.56$ & $<0.01$ \\
\hline$z$-BMI & $0.06 \pm 0.82$ & $1.69 \pm 0.44$ & $<0.01$ \\
\hline Systolic BP (mm Hg) & $90.40 \pm 11.67$ & $97.75 \pm 14.52$ & $<0.01$ \\
\hline Diastolic BP (mm Hg) & $55.08 \pm 8.59$ & $59.89 \pm 9.31$ & $<0.01$ \\
\hline Triglycerides (mg/dL) & $69.75 \pm 29.55$ & $87.94 \pm 44.05$ & $<0.01$ \\
\hline HDL-C (mg/dL) & $52.88 \pm 11.77$ & $47.46 \pm 11.09$ & $<0.01$ \\
\hline Glucose (mg/dL) & $75.83 \pm 8.89$ & $77.16 \pm 7.63$ & 0.04 \\
\hline Insulin (UI/mL) & $3.88 \pm 2.96$ & $7.15 \pm 5.27$ & $<0.01$ \\
\hline HOMA-IR & $0.74 \pm 0.61$ & $1.36 \pm 0.98$ & $<0.01$ \\
\hline Risk factors $\geq 1$ & $18.83 \%(16.03-21.62)$ & $75.32 \%(70.56-80.07)$ & $<0.01$ \\
\hline Hypertension & $3.0(1.76-4.23)$ & $13.1(9.39-16.89)$ & $<0.01$ \\
\hline High triglycerides & $6.6(4.53-8.71)$ & $21.7(16.31-27.05)$ & $<0.01$ \\
\hline WC $\geq 90$ th percentile & $5.6(3.96-7.26)$ & $69.6(64.55-74.69)$ & $<0.01$ \\
\hline Low HDL-C & $14.3(11.39-17.28)$ & $27.4(21.62-33.25)$ & $<0.01$ \\
\hline High glucose & $0.9(0.12-1.73)$ & $0.4(-0.42-1.31)$ & 0.67 \\
\hline Gender (Females) & $51.0 \%(382 / 749)$ & $50.0 \%(158 / 316)$ & 0.78 \\
\hline
\end{tabular}

Data are in Mean \pm SD and observed prevalence is in percentage and $95 \%$ confidence interval.

In order to analyze the probability of being OW/OB, we created a table to show the variation of this probability for each combination of values of HOMA-IR and health score (Table 4). Within the group of HOMA-IR < III quartile, the probability of OW/OB went from 0.33 to 0.11 moving from the category of the least healthy score to that of the healthiest, whereas in the group with insulin resistance (HOMA-IR $\geq$ III quartile), the probability of OW/OB went from 0.72 to 0.41 moving from the category of the least healthy score to that of the healthiest. 


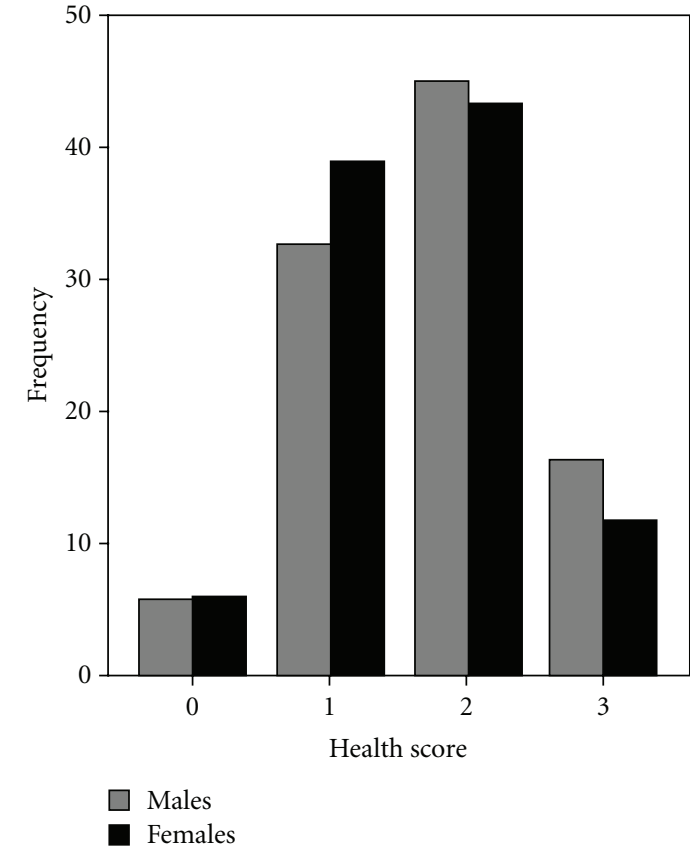

FIGURE 1: Health score distribution according to Gender.

TABLE 3: Multiple regression analysis.

\begin{tabular}{lccc}
\hline & $\begin{array}{c}\text { Standardized } \\
\text { coefficients } \\
\text { Beta }\end{array}$ & $T$ & Significance \\
& & 16.24 & 0.00 \\
Constant & -0.08 & -2.23 & 0.03 \\
Breakfast intake & -0.08 & -2.22 & 0.03 \\
Milk intake & -0.01 & -0.22 & 0.83 \\
Sweet drinks & -0.08 & -2.34 & 0.02 \\
TV viewing & 0.06 & 1.79 & 0.07 \\
Bocks walked & 0.03 & 0.91 & 0.36 \\
Fruit and vegetables & 0.06 & 1.58 & 0.11 \\
Family meals & 0.01 & 0.38 & 0.70 \\
TV in bedrooms &
\end{tabular}

Dependent variable: BMI percentiles. Independent variables: Lifestyle behaviors.

Multiple logistic regression analysis showed a direct association between children's OW/OB and HOMA-IR quartiles (OR, 2.42 (95\% CI 1.97-2.98)), and masculine gender (OR, 0.56 (95\% CI $0.37-0.85)$ ), and an inverse association with healthy score (OR, 0.66 (95\% CI $0.52-0.85)$ ) adjusted for Tanner stage. Therefore, when the score went from an unhealthy category to a healthier one, the chance for OW/OB decreased by $34 \%$ adjusted for HOMA-IR, gender, and Tanner. These results suggestthatunhealthy habits are associated with $\mathrm{OW} / \mathrm{OB}$.

\section{Discussion}

The most important finding in this report is that this simple healthy score, which included breakfast intake, milk

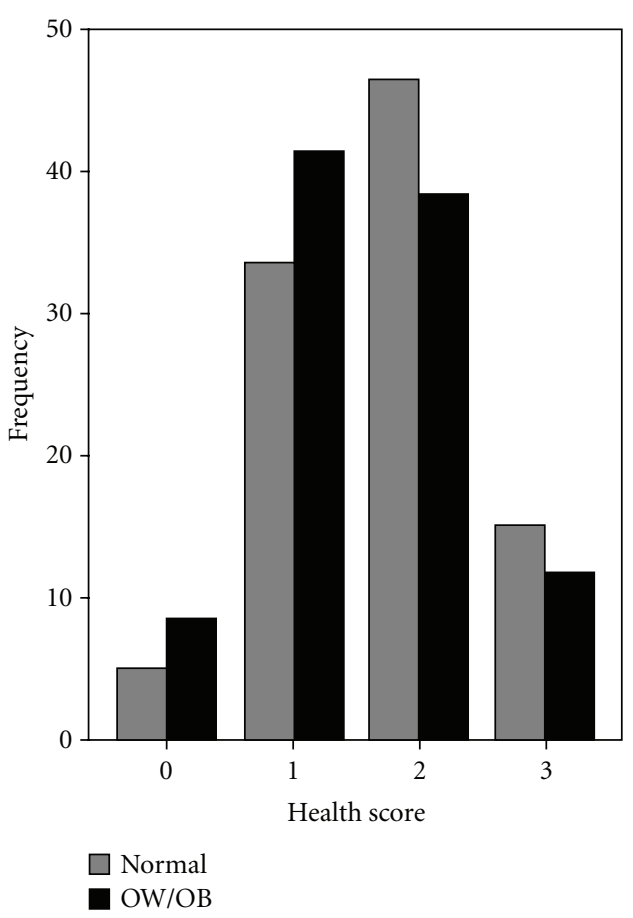

FIgURE 2: Health score distribution according to OW/OB.

TABLe 4: Probability of OW/OB for each combination of HOMA-IR quartiles and health score (from unhealthy to healthy).

\begin{tabular}{lcc}
\hline Health score & HOMA-IR $>$ III Quartile & $\begin{array}{c}\% \\
\text { OW/OB }\end{array}$ \\
\hline 0 & 0 & 32.92 \\
1 & 0 & 24.03 \\
2 & 0 & 16.94 \\
3 & 0 & 11.61 \\
0 & 1 & 71.94 \\
1 & 1 & 62.30 \\
2 & 1 & 51.57 \\
3 & 1 & 40.70 \\
\hline
\end{tabular}

consumption, and TV watching, is a strong predictor of children's OW/OB. The study also shows that there was a high prevalence of OW/OB in this low-income Argentinean school-children sample. Children with OW/OB have a higher prevalence of many components of the metabolic syndrome, including central obesity, hypertension, high triglycerides, low HDL-C, and high glucose, compared to normal weight children with similar age, sex, and pubertal development. It would, therefore, be reasonable to hypothesize that poor diet and lack of physical activity have contributed to the association between $\mathrm{OW} / \mathrm{OB}$ and insulin resistance in children.

The rise in the prevalence of OW/OB in children is one of the most alarming public health issues facing the world today. The 2003-2004 US National Health and Nutrition 
Examination Survey of 3958 children and adolescents aged 2 to 19 years found that $33.6 \%$ of children had a $\geq 85$ th percentile BMI [19]. The prevalence of OW/OB in this cohort of Argentinean socioeconomically deprived population ( $8 \%$ without refrigerators and 4\% with dirt floors), aged 5 to 14 years (30\%), was very similar to the alarming and increasing rate of OW/OB among children in the United States. Interestingly, the difference between our Argentine population and the National Health and Nutrition Examination Survey [19] is that the prevalence of OW/OB was not any worse than in a more affluent population, such as the USA.

The BMI has become a universal index of nutritional status in children. Consistent with data in adults and in children [20], we found that adiposity measured by BMI had a strong effect on differences in triglycerides, HDL-C, and insulinemia in both age groups and genders. Several mechanisms have been proposed to explain this, including impaired insulin signaling, interference with glucose transport, decreased insulin clearance related to elevated intraportal free fatty acids, and systemic effects of adipocyte cytokines [21, 22]. Consistent with these studies, we found that adiposity measured by BMI had a strong effect on differences in insulinemia. Results from the multiple regression analysis showed that BMI was associated with insulinresistance and unhealthy score. Different longitudinal studies [23-25] demonstrated that a reduction in body weight and lifestyle changes were associated with a reduction in cardiovascular disease and diabetes. The Bright Bodies study [23] demonstrated that changing the lifestyle of $\mathrm{OB}$ children, using a family-based program that used nutrition education, behavior modification, and supervised exercise, could lower BMI, improve body composition, and increase insulin sensitivity. The Look AHEAD research study [24] showed that intensive lifestyle intervention resulted in weight loss with improved cardiovascular risk factors in people with type 2 diabetes. The Young Finns study also showed that abdominal $\mathrm{OB}$ in adulthood was directly related to youth $\mathrm{OB}$, and maintaining physical activity from adolescence to adulthood helped to reduce OB [25]. Consistent with these studies, we found that childhood OW/OB was directly associated with insulin resistance and inversely associated with the health score, indicating more sedentary habits, and a less healthy diet was more prevalent in the group of school children with OW/OB.

Physicians should assess children for OW/OB risk to improve early identification of elevated BMI, unhealthy eating, and physical activity habits [26]. Dietary patterns have a role in the development of cardiovascular diseases due to the effects on their risk factors and body fatness. For prevention, the recommendations include eating healthy food, encouraging family meals, limiting portion sizes, and avoiding sedentary behaviors, which are likely to promote maintenance of a healthy weight [26]. These observations highlight the important role that lifestyle behaviors play in childhood OW/OB. The reported intake of healthy foods was low in this survey. Approximately 14\% of the children skipped breakfast, which is known to be associated with a decreased nutritional quality of the diets of children [27]. We also observed that $63 \%$ of the children watched TV more than two hours per day, which is associated with reduced energy expenditure from TV viewing displacing physical activity. Of particular note is the strong inverse association between healthy score, which included breakfast intake, milk consumption and TV watching, and OW/OB. Furthermore, we found that in the group of children without insulin resistance, the probability of being OW/OB decreased from $33 \%$ to $11 \%$ and in the group with insulin resistance the probability decreased from $72 \%$ to $41 \%$ with health scores in both groups going from the least healthy category to the healthiest. Our results from the multiple logistic regression analysis also showed that when the score went from an unhealthy category to a healthier one, the chance for OW/OB decreased by $34 \%$ adjusted for HOMA-IR, gender, and Tanner.

This study has several limitations. The cross-sectional data limit our ability to definitively identify which factors account for the unfavorable cardiovascular risk observed in OW/OB children compared with normal weight children. Additionally, there is a lack of consensus regarding specific criteria and cutoff values for insulin resistance, particularly in children. Despite these limitations, our findings of higher levels of insulin resistance and lower levels of lifestyle health scores in a large group of school children with OW/OB are important and also time observations about the potential burden of comorbidities in this population. Furthermore, the lack of a healthy lifestyle, such as excessive sedentary habits and a poor diet, increases the risk of OW/OB and future complications especially given that many cardiovascular risk factors encountered in children track from childhood into adulthood [28]. Lastly, as the sample included only elementary school children, only $4 \%$ of the children were at Tanner stage 4 . Therefore late puberty was not represented in the sample. However, the strengths of our study included our school sample, which was more likely to represent the general population of school children, the good response rate of the children, and the use of regression models and simultaneous adjustments of confounding variables.

\section{Conclusions}

Our results suggest that insulin resistance is directly associated with childhood OW/OB while healthy habits are inversely associated. The decrease in nutritional quality of the diets and reduced energy expenditure from sedentary habits displacing physical activity are associated with a higher prevalence of OW/OB and its complications. This is an easy score that could be used to predict children's OW/OB; however additional longitudinal studies should be done to confirm these findings.

\section{Abbreviations}

OW: Overweight

OB: Obesity

HOMA-IR: Homeostasis model assessment for insulin resistance. 


\section{Conflict of Interests}

The authors do not have a direct financial relation with SPSS that might lead to conflict of interests.

\section{References}

[1] S. A. Tanumihardjo, C. Anderson, M. Kaufer-Horwitz et al., "Poverty, obesity, and malnutrition: an international perspective recognizing the paradox," Journal of the American Dietetic Association, vol. 107, no. 11, pp. 1966-1972, 2007.

[2] V. Hirschler, K. Buzzano, A. Erviti, N. Ismael, S. Silva, and R. Dalamon, "Overweight and lifestyle behaviors of low socioeconomic elementary school children in Buenos Aires," BMC Pediatrics, vol. 9, no. 1, article no. 17, 2009.

[3] S. S. Guo, W. Wu, W. C. Chumlea, and A. F. Roche, "Predicting overweight and obesity in adulthood from body mass index values in childhood and adolescence," American Journal of Clinical Nutrition, vol. 76, no. 3, pp. 653-658, 2002.

[4] J. M. Saland, "Update on the metabolic syndrome in children," Current Opinion in Pediatrics, vol. 19, no. 2, pp. 183-191, 2007.

[5] J. J. Reilly, E. Methven, Z. C. McDowell et al., "Health consequences of obesity," Archives of Disease in Childhood, vol. 88, no. 9, pp. 748-752, 2003.

[6] D. S. Freedman, D. A. Patel, S. R. Srinivasan et al., "The contribution of childhood obesity to adult carotid intimamedia thickness: the bogalusa heart study," International Journal of Obesity, vol. 32, no. 5, pp. 749-756, 2008.

[7] M. Juonala, J. S. A. Viikari, T. Rönnemaa et al., "Associations of dyslipidemias from childhood to adulthood with carotid intima-media thickness, elasticity, and brachial flow-mediated dilatation in adulthood: the Cardiovascular Risk in Young Finns Study," Arteriosclerosis, Thrombosis, and Vascular Biology, vol. 28, no. 5, pp. 1012-1017, 2008.

[8] V. Hirschler, M. I. Roque, M. L. Calcagno, C. Gonzalez, and C. Aranda, "Maternal waist circumference and the prediction of children's metabolic syndrome," Archives of Pediatrics and Adolescent Medicine, vol. 161, no. 12, pp. 1205-1210, 2007.

[9] W. Willett, Nutritional Epidemiology, Oxford University Press, New York, NY, USA, 2nd edition, 1998.

[10] "Dietary Guideline Advisory Committee. Nutrition and your health: dietary guidelines for Americans," 2005, http:// www.health.gov/dietaryguidelines/dga2005/report/HTML/E_ translation.htm.

[11] J. M. Tanner, Growth at Adolescence: With a General Consideration of the Effects of Hereditary and Environmental Factors upon Growth and Maturation from Birth to Maturity, Blackwell Scientific, Oxford, UK, 2nd edition, 1962.

[12] "Composición étnica de Argentina," http://es.wikipedia.org/ wiki/Composición_étnica_de_Argentina.

[13] R. J. Kuczmarski, C. L. Ogden, S. S. Guo et al., “2000 CDC Growth Charts for the United States: methods and development," Vital and Health Statistics, no. 246, pp. 1-190, 2002.

[14] B. Falkner, S. R. Daniels, J. T. Flynn et al., "The fourth report on the diagnosis, evaluation, and treatment of high blood pressure in children and adolescents," Pediatrics, vol. 114, no. 2 III, pp. 555-576, 2004.

[15] S. Cook, M. Weitzman, P. Auinger, M. Nguyen, and W. H. Dietz, "Prevalence of a metabolic syndrome phenotype in adolescents," Archives of Pediatrics and Adolescent Medicine, vol. 157, no. 8, pp. 821-827, 2003.
[16] D. R. Matthews, J. P. Hosker, A. S. Rudenski, B. A. Naylor, D. F. Treacher, and R. C. Turner, "Homeostasis model assessment: insulin resistance and $\beta$-cell function from fasting plasma glucose and insulin concentrations in man," Diabetologia, vol. 28, no. 7, pp. 412-419, 1985.

[17] D. Young-Hyman, D. G. Schlundt, L. Herman, F. De Luca, and D. Counts, "Evaluation of the insulin resistance syndrome in 5- to 10-year-old overweight/obese African-American children," Diabetes Care, vol. 24, no. 8, pp. 1359-1364, 2001.

[18] K. A. Mcauley, S. M. Williams, J. I. Mann et al., "Diagnosing insulin resistance in the general population," Diabetes Care, vol. 24, no. 3, pp. 460-464, 2001.

[19] C. L. Ogden, M. D. Carroll, L. R. Curtin, M. A. McDowell, C. J. Tabak, and K. M. Flegal, "Prevalence of overweight and obesity in the United States, 1999-2004," Journal of the American Medical Association, vol. 295, no. 13, pp. 1549-1555, 2006.

[20] G. Perez Gomez and F. G. Huffman, "Risk factors for type 2 diabetes and cardiovascular diseases in hispanic adolescents," Journal of Adolescent Health, vol. 43, no. 5, pp. 444-450, 2008.

[21] B. B. Kahn and J. S. Flier, "Obesity and insulin resistance," Journal of Clinical Investigation, vol. 106, no. 4, pp. 473-481, 2000.

[22] A. M. G. Cali and S. Caprio, "Prediabetes and type 2 diabetes in youth: an emerging epidemic disease?" Current Opinion in Endocrinology, Diabetes and Obesity, vol. 15, no. 2, pp. 123127, 2008.

[23] M. Savoye, M. Shaw, J. Dziura et al., "Effects of a weight management program on body composition and metabolic parameters in overweight children: a randomized controlled trial," Journal of the American Medical Association, vol. 297, no. 24, pp. 2697-2704, 2007.

[24] M. Espeland, X. Pi-Sunyer, G. Blackburn et al., "Reduction in weight and cardiovascular disease risk factors in individuals with type 2 diabetes," Diabetes Care, vol. 30, no. 6, pp. 13741383, 2007.

[25] X. Yang, R. Telama, E. Leskinen, K. Mansikkaniemi, J. Viikari, and O. T. Raitakari, "Testing a model of physical activity and obesity tracking from youth to adulthood: the cardiovascular risk in young Finns study," International Journal of Obesity, vol. 31, no. 3, pp. 521-527, 2007.

[26] S. E. Barlow, "Expert committee recommendations regarding the prevention, assessment, and treatment of child and adolescent overweight and obesity: summary report," Pediatrics, vol. 120, supplement, pp. S164-192, 2007.

[27] T. A. Nicklas, C. O'Neil, and L. Myers, “The importance of breakfast consumption to nutrition of children, adolescents, and young adults," Nutrition Today, vol. 39, pp. 30-39, 2004.

[28] M. Charakida, J. E. Deanfield, and J. P. Halcox, "Childhood origins of arterial disease," Current Opinion in Pediatrics, vol. 19, no. 5, pp. 538-545, 2007. 


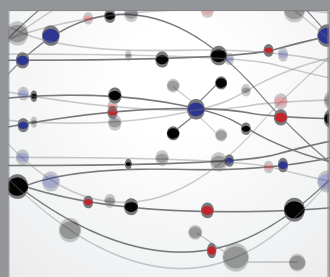

The Scientific World Journal
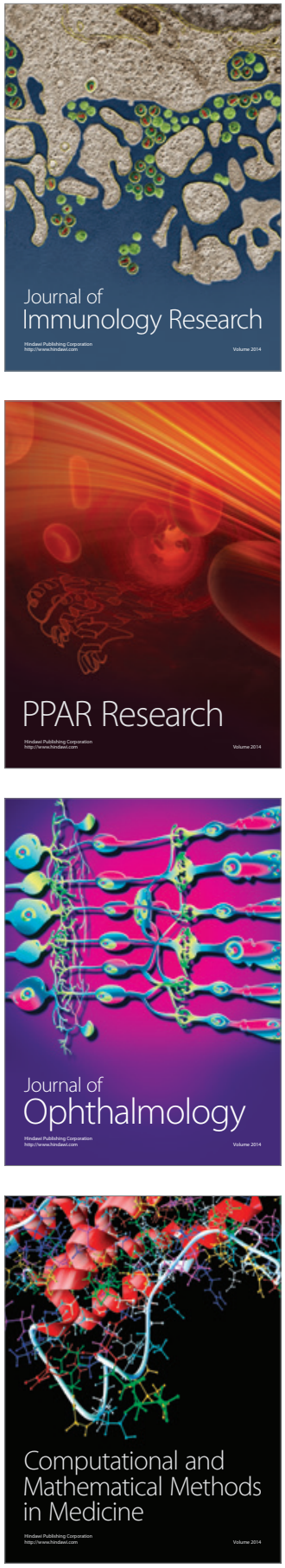

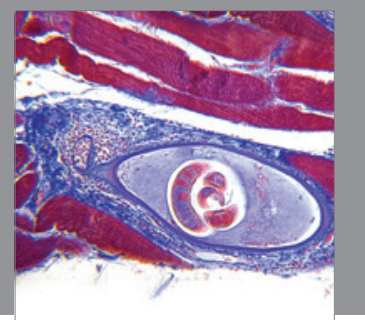

Gastroenterology

Research and Practice
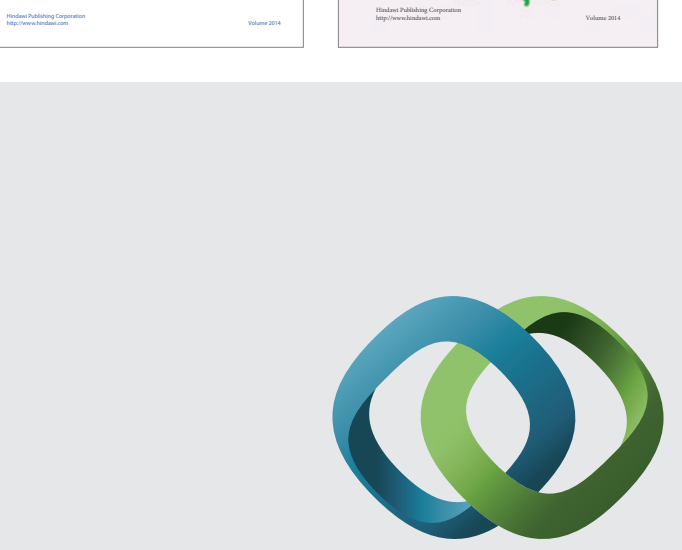

\section{Hindawi}

Submit your manuscripts at

http://www.hindawi.com
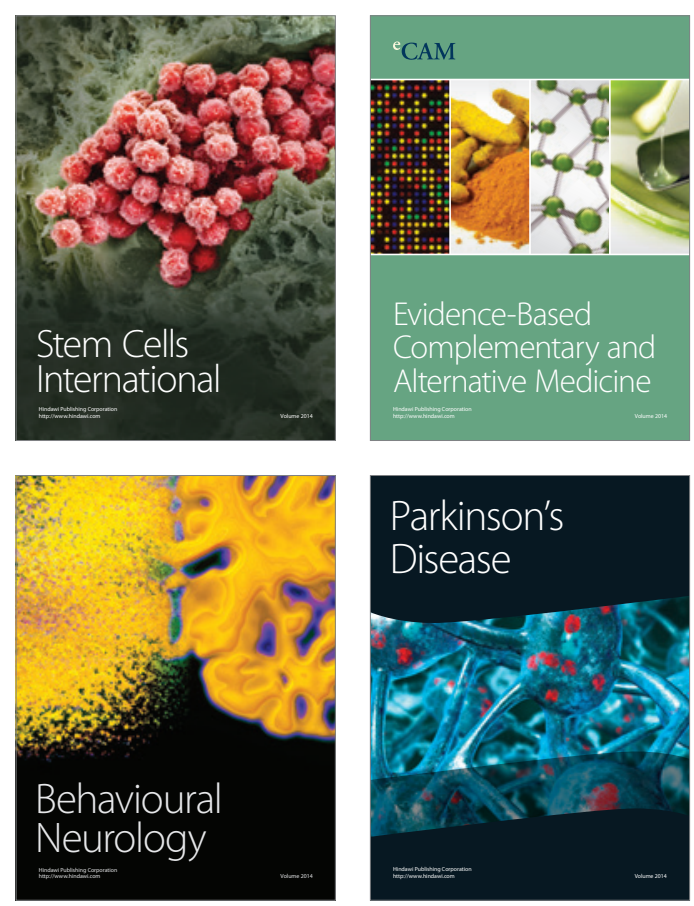

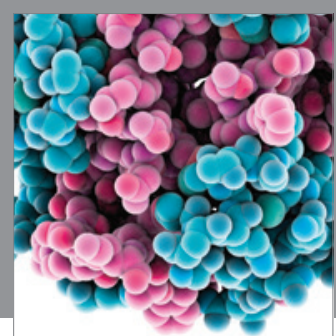

Journal of
Diabetes Research

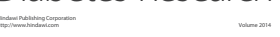

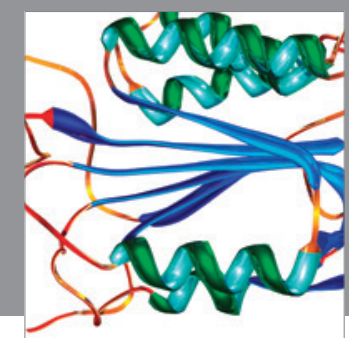

Disease Markers
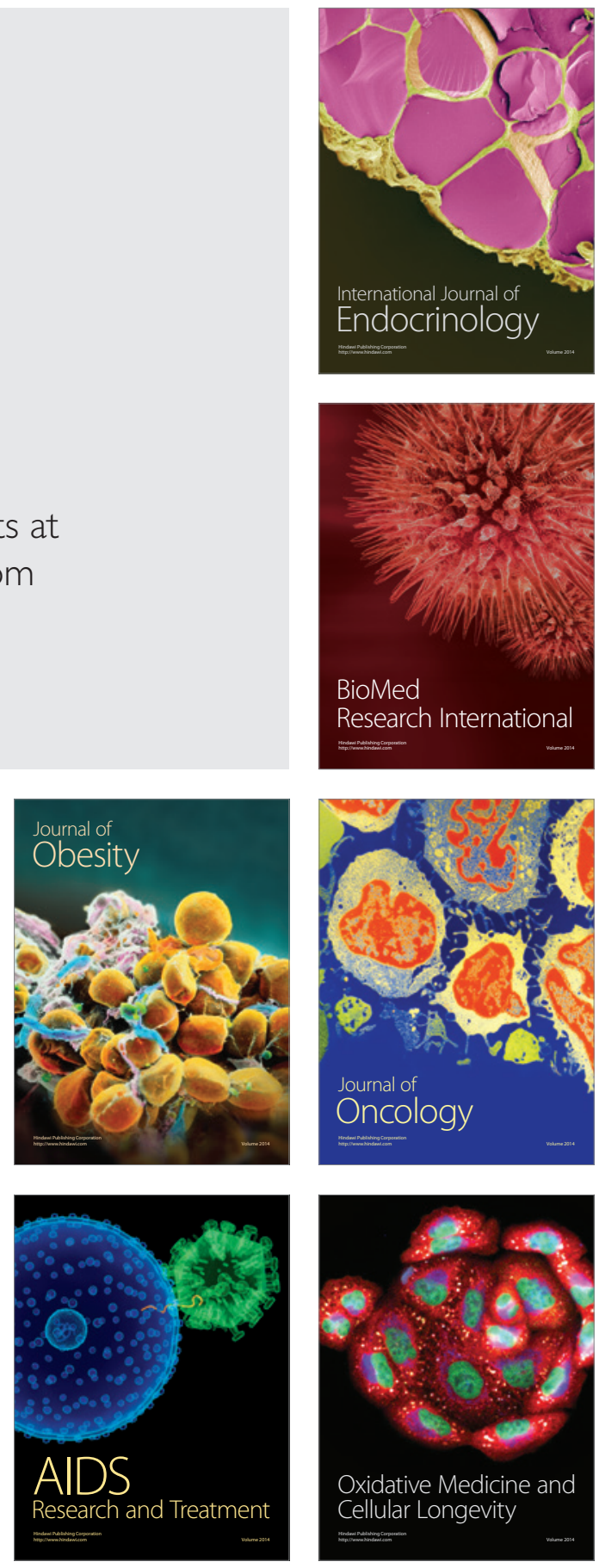